\title{
New insights into the mechanism of action of acetaminophen: Its clinical pharmacologic characteristics reflect its inhibition of the two prostaglandin $\mathrm{H}_{2}$ synthases
}

\author{
David M. Aronoff, MD, John A. Oates, MD, and Olivier Boutaud, PhD Ann Arbor, \\ Mich, and Nashville, Tenn
}

Acetaminophen (INN, paracetamol) possesses highly selective analgesic and antipyretic effects that result from its inhibitory actions on the synthesis of prostaglandins (PGs). PGs are lipid mediators derived from arachidonic acid that play central roles in the pathogenesis of inflammation, fever, and pain. ${ }^{1}$ However, acetaminophen differs from the majority of nonsteroidal anti-inflammatory drugs (NSAIDs) and selective inhibitors of prostaglandin $\mathrm{H}_{2}$ synthase (PGHS) 2 because it lacks significant antiinflammatory activity. ${ }^{2}$ Moreover, as opposed to aspirin, acetaminophen is a poor inhibitor of platelet function at doses that are antipyretic., ${ }^{3,4}$

PGs are generated by the oxygenation of arachidonic acid to the unstable intermediate prostaglandin $\mathrm{H}_{2}$ $\left(\mathrm{PGH}_{2}\right)$ by PGHS, of which there are 2 major isoforms - the constitutive PGHS-1 and the (generally) inducible PGHS-2 (discussed later). ${ }^{5}$ These enzymes are also commonly referred to as cyclooxygenase (COX) 1 and 2, respectively, in reference to the specific enzymatic active site that catalyzes arachidonic acid oxygenation and provides the target for the majority of

From the Division of Infectious Diseases, Department of Internal Medicine, University of Michigan Health System, Ann Arbor, and Departments of Internal Medicine and Pharmacology, Division of Clinical Pharmacology, Vanderbilt University, Nashville.

Financial support was provided by National Institutes of Health grants HL007749 and GM15431, the Parker B. Francis Foundation, and grants from Merck-Frosst and McNeil.

Received for publication July 25, 2005; accepted Sept 15, 2005.

Reprint requests: Olivier Boutaud, PhD, Division of Clinical Pharmacology, Department of Pharmacology, Vanderbilt University, Nashville, TN 37232-6602.

E-mail: olivier.boutaud@vanderbilt.edu

Clin Pharmacol Ther 2006;79:9-19.

0009-9236/\$32.00

Copyright $\odot 2006$ by the American Society for Clinical Pharmacology and Therapeutics.

doi:10.1016/j.clpt.2005.09.009 pharmacologic inhibitors of these enzymes (discussed later). However, in this commentary we use the term PGHS to describe the enzymes and limit the use of $C O X$ to refer specifically to the PGHS cyclooxygenase active site and $P O X$ to refer to the PGHS peroxidase active site (as discussed in the "Catalytic mechanisms of PGHS" section).

Acetaminophen is an inhibitor of both PGHS isoforms in purified enzyme preparations. ${ }^{6}$ However, it exhibits a highly variable capacity to inhibit PG synthesis by different cell and tissue types. For example, the analgesic and antipyretic effects of acetaminophen follow its inhibition of prostaglandin $\mathrm{E}_{2}\left(\mathrm{PGE}_{2}\right)$ generation within the central nervous system (CNS), ${ }^{7,8}$ whereas the failure of acetaminophen to inhibit plateletderived thromboxane $\mathrm{A}_{2}$ synthesis ${ }^{9}$ and inflammatory $\mathrm{PGE}_{2}$ synthesis ${ }^{10}$ accords with its weak antiplatelet and anti-inflammatory effects. Recent investigations of the mechanism of action of acetaminophen on the PGHSs have elucidated the basis for this cellular selectivity. This commentary brings together past investigations and recent insights regarding the nature of acetaminophen-PGHS interactions and provides a model that best explains the selective clinical behavior of acetaminophen.

\section{MECHANISM OF ACTION OF ACETAMINOPHEN}

In the latter half of the 19th century, phenacetin and acetaminophen, structurally related aniline dye derivatives, were developed as antipyretic agents. ${ }^{11,12}$ The safety profile of phenacetin was mistakenly favored over acetaminophen, leading to the popular clinical use of the former drug for nearly 80 years. ${ }^{13}$ However, in the late 1940s Brodie and Axelrod ${ }^{14}$ elegantly demonstrated that phenacetin's therapeutic efficacy was a 


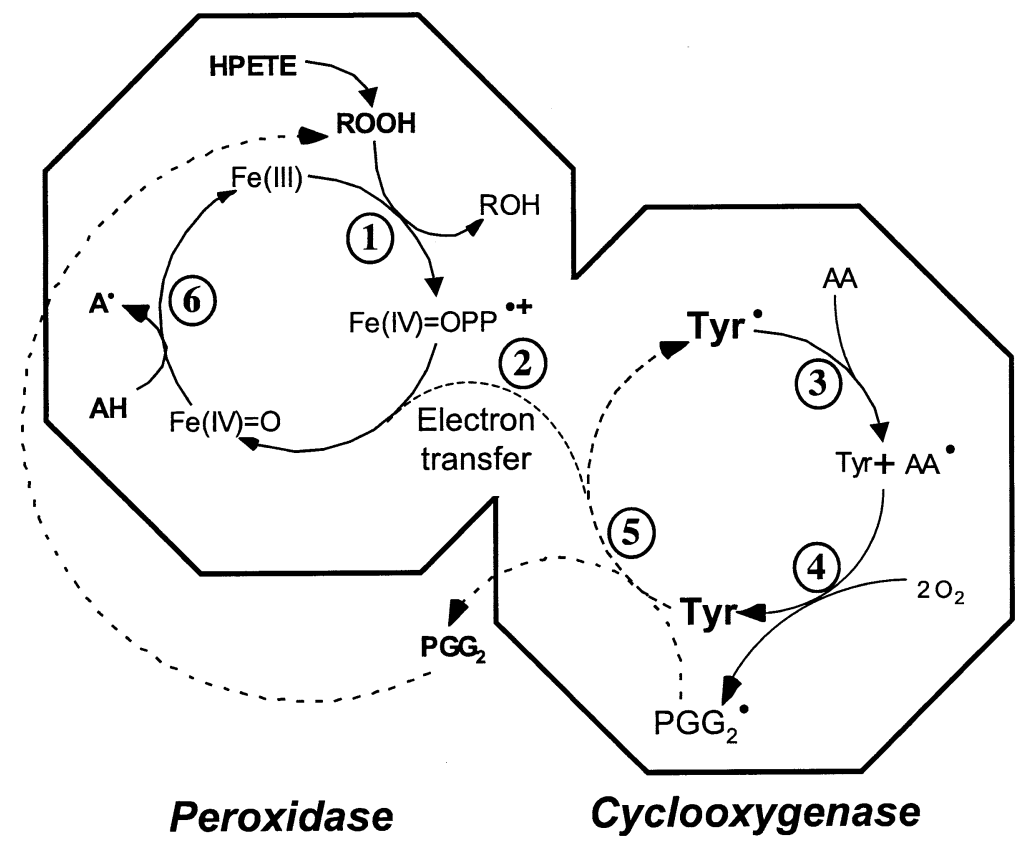

Fig 1. Catalytic mechanism of prostaglandin $H$ synthases as proposed by Karthein et al. ${ }^{32}$ The different steps are described in the text. $\mathrm{Fe}(\mathrm{IV})=\mathrm{OPP}^{\bullet+}$, Ferryl protoporphyrin IX radical cation; $\mathrm{FE}(\mathrm{III})$, resting enzyme; $\mathrm{Fe}(\mathrm{IV})=\mathrm{O}$, ferryl protoporphyrin IX; $\mathrm{Tyr}^{\bullet}$, tyrosine 385 radical; $\mathrm{AH}$, reducing cosubstrate; $\mathrm{AA}$, arachidonic acid; $\mathrm{AA}^{\bullet}$, arachidonic acid radical; $\mathrm{PGG}_{2}$, prostaglandin $\mathrm{G}_{2}$; $\mathrm{PGG}_{2}{ }^{\bullet}$, prostaglandin $\mathrm{G}_{2}$ with peroxyl radical on carbon 15 ; ROOH, hydroperoxide substrate; $\mathrm{ROH}$, alcohol product; $\mathrm{A}^{\bullet}$, oxidized cosubstrate; HPETE, hydroperoxide of fatty acids.

result of its major hepatic metabolite, acetaminophen. These seminal experiments published in the Journal of Pharmacology and Experimental Therapeutics were among the first to demonstrate the pharmacologic activity of a drug metabolite formed in vivo and resulted in the rapid popularization of acetaminophen for clinical use. Within 2 decades, acetaminophen was shown to reduce prostaglandin $\mathrm{E}$ production in vivo, ${ }^{15}$ inciting researchers to investigate the molecular basis for such effects.

\section{Biochemical differences within cells that affect acetaminophen-PGHS interactions}

Catalytic mechanisms of PGHS. PGHSs catalyze the oxygenation of arachidonic acid to yield $\mathrm{PGH}_{2}$. This reaction occurs in 2 steps catalyzed by distinct active sites within the same enzyme. ${ }^{16}$ The hydrogen atom on carbon 13 of arachidonic acid is abstracted by the tyrosine 385 radical present in the COX active site. The resulting arachidonyl radical incorporates 2 molecules of oxygen to yield the hydroperoxyendoperoxide intermediate prostaglandin $\mathrm{G}_{2}\left(\mathrm{PGG}_{2}\right) . \mathrm{PGG}_{2}$ then undergoes a 2-electron reduction to the equivalent alco- hol, $\mathrm{PGH}_{2}$, in the POX catalytic site. The reduction of hydroperoxides in the POX site yields an oxidized heme radical, which generates the tyrosine 385 radical in the COX site via intramolecular electron transfer.

As stated previously, initiation of COX-catalyzed arachidonic acid oxygenation requires that the tyrosine 385 residue within the active site must first be oxidized to a radical $\left(\mathrm{Tyr}^{\bullet}\right)$ (Fig 1). This priming event is made possible by the initial reduction of an available hydroperoxide substrate by the POX site, generating a ferryl protoporphyrin IX radical cation [Fe(IV)PP ${ }^{\bullet+}$ ] (Fig 1, step 1). The POX site can reduce a broad range of hydroperoxides with variable efficacy: hydroperoxides of fatty acids are preferential substrates, whereas hydrogen peroxide is a very weak substrate. ${ }^{16}$ The $\mathrm{Fe}(\mathrm{IV}) \mathrm{PP}^{\bullet+}$ radical can then be transferred to the neighboring Tyr 385 in the COX active site, yielding the requisite $\mathrm{Tyr}^{\bullet}$ and a partially reduced form of the heme [Fe(IV)] (Fig 1, step 2), which must be further reduced by 1 electron to regenerate the resting enzyme [Fe(III)] (Fig 1, step 6). This heme reduction is performed by any number of reducing cosubstrates within cells that have not been characterized. Using phenol, 
Harvison et $\mathrm{al}^{17}$ were first able to demonstrate that reducing cosubstrates was necessary for POX activity. Since then, many molecules have been characterized as POX cosubstrates with variable efficiencies. ${ }^{18}$ These molecules facilitate the regeneration of the resting enzyme, a process that is necessary for starting a new POX cycle.

The $\mathrm{Tyr}^{\bullet}$ initiates the oxygenation of arachidonic acid by abstracting a proton from $\mathrm{C}-13$ of the molecule (Fig 1, step 3), generating a radical species that is further oxidized by 2 molecules of oxygen (Fig 1, step 4). This process yields a $\mathrm{PGG}_{2}$ radical that is reduced to $\mathrm{PGG}_{2}$, regenerating the $\mathrm{Tyr}^{\bullet}$ in the process (Fig 1, step 5 ; mechanism extensively reviewed in references ${ }^{19}$ and ${ }^{20}$ ). However, some "leakage" of the $\mathrm{PGG}_{2}$ radical from the COX active site can occur, thereby interrupting the COX cycle that regenerates the $\mathrm{Tyr}^{\bullet}$; this necessitates reactivation of COX activity by heme-dependent hydroperoxide reduction.

The COX active site is the target of the majority of NSAIDs, as well as the COX-2-specific inhibitors, which essentially inhibit PGHS function by the same mechanism, that is, noncovalently binding within the COX site to physically obstruct entry of arachidonic acid (aspirin is unique among these inhibitors by virtue of its ability to covalently modify the COX site). However, this mechanism is not shared by acetaminophen, which was not found to inhibit PGHSs from within the COX site. This was evidenced by its inability to protect the enzyme against the time-dependent COX inhibition by indomethacin (INN, indometacin), diclofenac, or aspirin. $^{3,21}$ In fact, acetaminophen appears to inhibit PGHS activity through its capacity to serve as a reducing cosubstrate for the POX active site. ${ }^{17,18,22-26}$ In the next sections we illustrate this unique mechanism of inhibition and explain how ambient levels of hydroperoxide molecules might prevent acetaminophen's action.

Acetaminophen-PGHS interactions. After the discovery that both constitutive and inducible isoforms of PGHS exist, ${ }^{27}$ it was realized that inhibitors might exhibit selectivity toward one isoform over the other. ${ }^{28}$ However, the selective inhibition of either PGHS-1 or -2 would not explain acetaminophen's poor inhibitory activity against both platelets (which only express PGHS-1) and activated leukocytes (which rely on PGHS-2 for eicosanoid production). In fact, in vitro assays of purified PGHS-1 and -2 enzyme preparations demonstrate either no isoform selectivity ${ }^{6}$ or a greater tendency of acetaminophen to inhibit PGHS-1. ${ }^{21}$ It appears most likely that acetaminophen inhibits cellular PGHS-1 or -2 (or both), depending on the cell type and experimental conditions (discussed later). For example,
PGHS-1-expressing cells of different lineage were found to exhibit variable susceptibilities to inhibition by acetaminophen. ${ }^{29}$

The understanding that acetaminophen inhibits PGHSs by reducing the higher oxidative state of the enzymes derives from an accumulation of evidence. Numerous in vitro studies have demonstrated that acetaminophen can reduce the higher oxidative state of the PGHS-POX (and other peroxidase enzymes) to the ferric [Fe(III)] or "resting" state. ${ }^{17,18,23}$ The capacity of acetaminophen to act as a reducing cosubstrate for PGHS-POX is illustrated in Fig 2, A. It would be predicted from this that reduction of the POX heme by acetaminophen would produce oxidized radicals of the drug, which has indeed been shown, ${ }^{22,24,25}$ and this reaction is dependent on generation of $\mathrm{PGG}_{2}$ by arachidonic acid oxidation in the COX active site. ${ }^{26}$ By contrast, ibuprofen, indomethacin, and flurbiprofen, inhibitors that block access of substrates to the PGHSCOX catalytic site, do not act as cosubstrates of PGHS-POX. ${ }^{18}$

As illustrated in Fig 2, $B$, the reduction of the POX heme to its resting state by acetaminophen essentially reverses the hydroperoxide-driven oxidation of the heme moiety. Accordingly, it was envisioned that acetaminophen could most effectively keep the PGHS in a resting state when the concentration of peroxide is low. Hanel and Lands ${ }^{30}$ hypothesized that peroxides, by oxidizing the enzyme to its catalytically active state, would oppose the action of drugs that reduce the oxidized form(s) of the enzyme back to the catalytically inactive resting state. They provided evidence for this by demonstrating that lowering the peroxide concentration with the enzyme glutathione peroxidase enhanced the inhibitory action of a number of reducing agents on PGHS-1, including acetaminophen; this finding has recently been extended to PGHS-2. ${ }^{21}$ This effect of peroxide concentration is consistent with the catalytic mechanism of PGHSs, in which the $\mathrm{Tyr}^{\bullet}$ in the PGHS-COX site is required for the COX activity (Fig 2, B). ${ }^{31,32}$

Increasing the concentration of the arachidonic acid substrate attenuates the inhibitory action of acetaminophen by elevating levels of $\mathrm{PGG}_{2}$. Increasing the concentration of arachidonic acid has been shown to reduce the inhibitory action of acetaminophen on the purified PGHSs. 6,21,33 This phenomenon would appear to be the consequence of the elevated level of $\mathrm{PGG}_{2}$ formed by the increased concentration of substrate, rather than a result of a competition of acetaminophen with arachidonic acid at the COX active site, because it has been reported that acetaminophen does not prevent the inhi- 

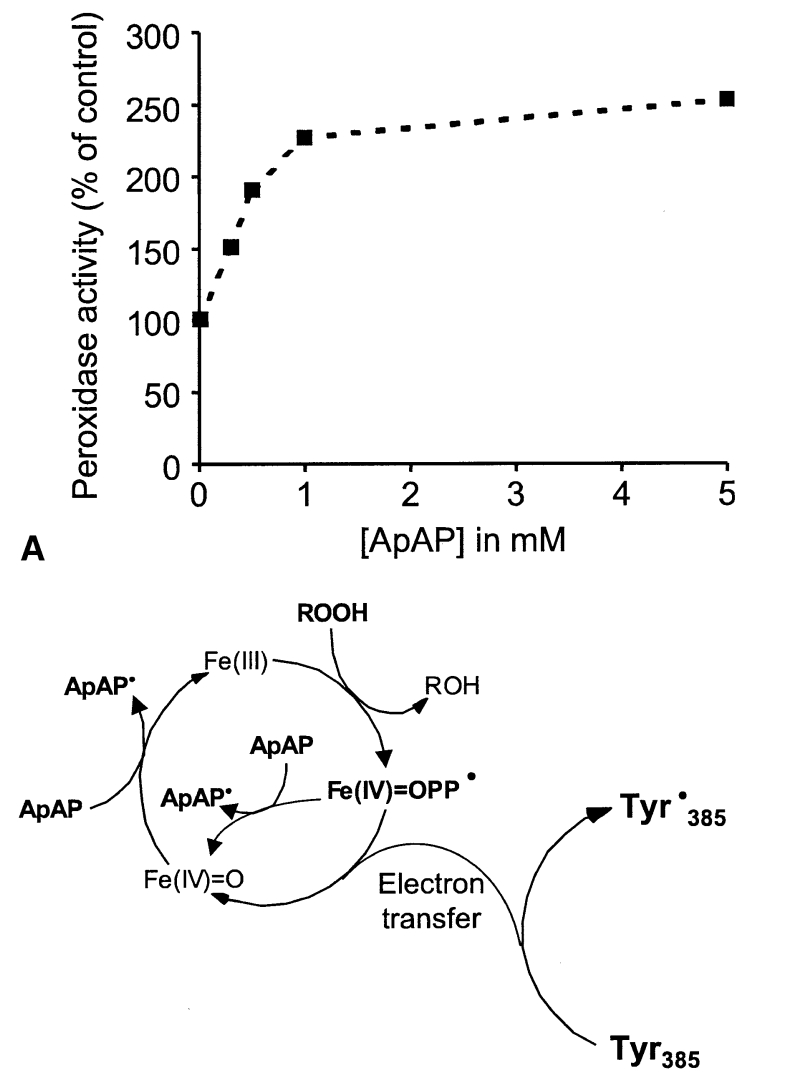

\section{B Peroxidase}

Cyclooxygenase

Fig 2. A, Effect of acetaminophen on prostaglandin $\mathrm{H}_{2}$ synthase (PGHS) 1 peroxidase function. Conversion of PPHP to PPA by ovine PGHS-1 reconstituted with hematin was monitored as a function of the concentration of acetaminophen, as described by Aronoff et al. ${ }^{64}$ The PGHS-peroxidase activity is expressed as a percentage of the control to which no acetaminophen was added. Each data point represents the mean \pm SEM of 6 values. (Adapted with permission from Aronoff DM, Boutaud O, Marnett LJ, Oates JA. Inhibition of prostaglandin $\mathrm{H} 2$ synthases by salicylate is dependent on the oxidative state of the enzymes. J Pharmacol Exp Ther 2003; 304:589-95.) B, Hypothetic mechanism of inhibition of PGHS by acetaminophen. Acetaminophen reduces $\mathrm{Fe}(\mathrm{IV})=\mathrm{OPP}^{\bullet+}$ to $\mathrm{Fe}(\mathrm{IV})=\mathrm{O}$. This reaction competes with the electron transfer between the tyrosine 385 residue and the heme radical, which yields the tyrosine radical in the cyclooxygenase active site. Acetaminophen also provides the second electron necessary to the regeneration of $\mathrm{Fe}(\mathrm{III})$, a process that is prerequisite for starting a new peroxidase cycle. PPHP, 5-Phenyl-4-pentenyl hydroperoxide; PPA, 5-phenyl4-pentenyl alcohol; ApAP, acetaminophen; ApAP, acetaminophen radical.

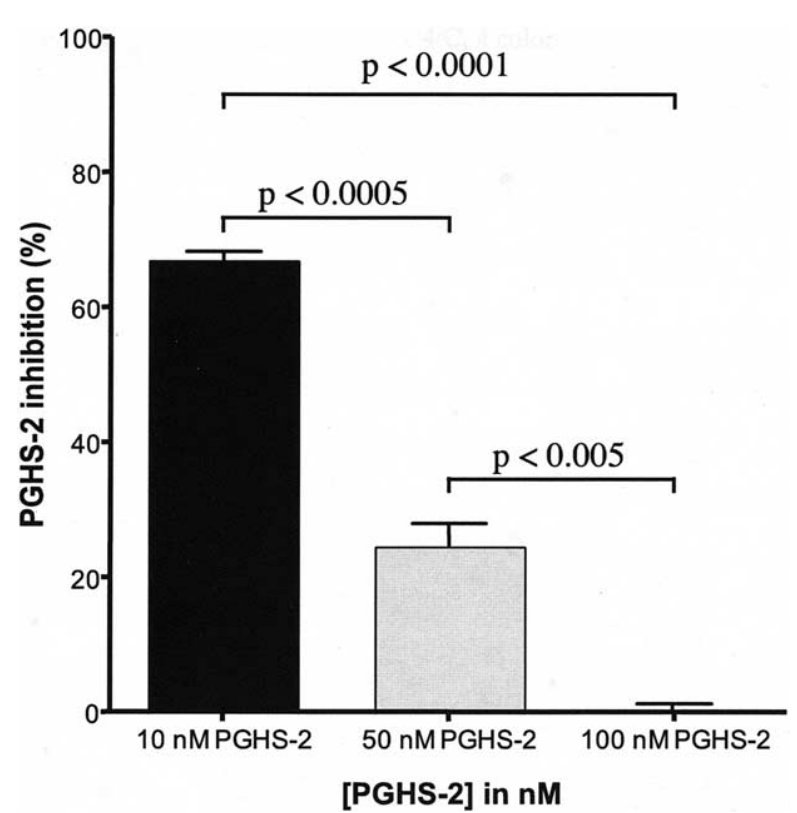

Fig 3. Effect of concentration of enzyme on inhibition of PGHS-2 by acetaminophen. Inhibition by $1-\mathrm{mmol} / \mathrm{L}$ acetaminophen of arachidonic acid oxygenation by different concentrations of purified PGHS-2 was monitored as described by Boutaud et al. ${ }^{6}$ The percentage of PGHS- 2 inhibition by acetaminophen is represented. Each data point represents the mean \pm SEM of 3 values. The significance between each concentration of enzyme was determined by the 2-tailed Student $t$ test.

bition of the enzyme by either indomethacin or aspirin. ${ }^{3,21}$ Confirming this hypothesis, similar results were obtained when exogenous $\mathrm{PGG}_{2}$ was added to the reaction vessel. ${ }^{6}$

In studies with purified PGHSs, the concentration of $\mathrm{PGG}_{2}$ also can be increased by raising the concentration of the enzyme. Thus we demonstrated that the inhibitory potency of acetaminophen could be significantly diminished by increasing the amount of PGHS enzyme present (Fig 3). These results essentially rule out a direct competition between arachidonic acid and acetaminophen because their ratio does not change under these experimental conditions. The concept that the inhibitory potency of acetaminophen is determined by the concentration of enzyme becomes very important when assaying the inhibition of PGHSs by acetaminophen. Thus comparison of the inhibitory potency of acetaminophen for different PGHS isoforms must be made with amounts of the isoforms that have the same catalytic activity. As seen in Fig 4, the potency of acetaminophen is markedly enhanced when low con- 


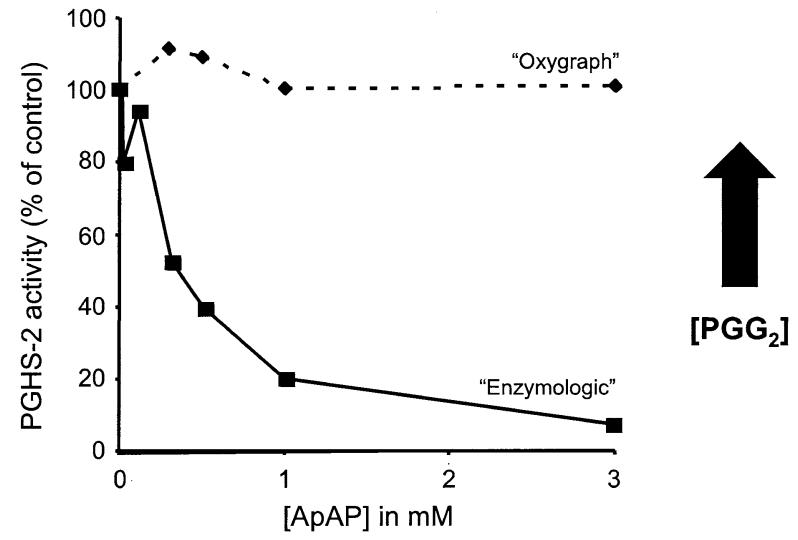

Fig 4. Effect of experimental conditions on inhibition by acetaminophen of PGHS-2. Inhibition of PGHS-2 activity by acetaminophen was monitored in different experimental conditions. Carbon 14 arachidonic acid was incubated with the enzyme at $37^{\circ} \mathrm{C}$ as described later. After 8 seconds, the reaction was terminated and the oxidized products were monitored by scanning thin-layer chromatography as described in reference 64. "Typical" oxygraph conditions consisted of performing the assay in the presence of 200-nmol/L PGHS-2 and $50-\mu \mathrm{mol} / \mathrm{L}$ arachidonic acid. "Enzymologic" conditions consisted of performing the assay in the presence of 10$\mathrm{nmol} / \mathrm{L}$ PGHS-2 and $0.5-\mu \mathrm{mol} / \mathrm{L}$ arachidonic acid. The arrow represents the increase of $\mathrm{PGG}_{2}$ produced by PGHS- 2 in the different conditions.

centrations of both substrate and enzyme are used. With the high substrate and enzyme concentrations used in oxygraph experiments, acetaminophen is unable to inhibit PGHS-2 at concentrations as high as $3 \mathrm{mmol} / \mathrm{L}$, whereas the $50 \%$ inhibitory concentration $\left(\mathrm{IC}_{50}\right)$ falls within the micromolar range when assayed in conditions of low substrate and low enzyme concentrations that favor low peroxide tone.

Influence of cellular peroxide tone on acetaminophen function. The aforementioned discovery that acetaminophen's inhibitory potency against PGHS could be antagonized by hydroperoxides (such as $\mathrm{PGG}_{2}$ ) suggests that intracellular hydroperoxide levels (the "peroxide tone" of the cell) might best explain the ability of the drug to block prostanoid synthesis in a cell-specific manner. For example, the potency of acetaminophen against platelet PGHS-1 when the concentration of exogenous arachidonic acid was $0.5 \mu \mathrm{mol} / \mathrm{L}\left(\mathrm{IC}_{50}=\right.$ $210 \mu \mathrm{mol} / \mathrm{L}$ ) was much lower than that observed if the arachidonic acid concentration was $20 \mu \mathrm{mol} / \mathrm{L}\left(\mathrm{IC}_{50}\right.$ $>3000 \mu \mathrm{mol} / \mathrm{L}$ ). ${ }^{6}$ To explore this hypothesis, we have characterized the effect of acetaminophen on cells that are germane to the pharmacologic selectivity of acet-

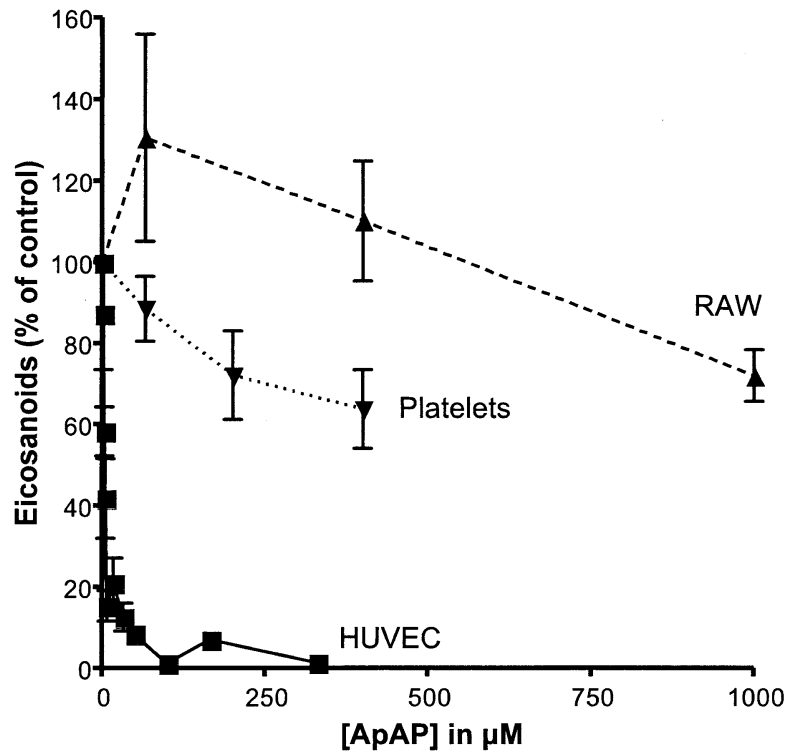

Fig 5. Comparative inhibition by acetaminophen of prostanoid synthesis by human platelets, human umbilical vein endothelial cells (HUVECs), and RAW 264.7. Synthesis of 6-keto-prostaglandin $\mathrm{F}_{1 \alpha}$ in HUVECs, thromboxane $\mathrm{B}_{2}$ in washed human platelets, and prostaglandins $\mathrm{E}_{2}$ and $\mathrm{D}_{2}$ in RAW 264.7 was assayed in the presence of increasing concentrations of acetaminophen. Arachidonic acid was added at a final concentration of $2.0 \mu \mathrm{mol} / \mathrm{L}$. After 15 minutes at $37^{\circ} \mathrm{C}$, prostanoids were extracted on a SepPak (Waters Corp, Milford, Mass) cartridge and derivatized for analysis by gas chromatography-negative ion chemical ionization-mass spectrometry as described in reference 65 . The concentration of prostanoids present in the medium is represented as a percent of the control to which no acetaminophen was added. Each data point represents the mean \pm SEM of at least 3 values.

aminophen (Fig 5). These investigations have been facilitated by our development of the pyrogenstimulated human umbilical vein endothelial cell (HUVEC) model and the demonstration of potent inhibition of epoprostenol (previously known as prostacyclin) biosynthesis by acetaminophen in these cells when low levels of exogenous arachidonic acid are provided as substrates. ${ }^{6}$ In interleukin $1 \alpha$-stimulated endothelial cells (which predominantly express PGHS-2), the $\mathrm{IC}_{50}$ of acetaminophen in the presence of $20 \mu \mathrm{mol} / \mathrm{L}$ of arachidonic acid $(72 \mu \mathrm{mol} / \mathrm{L})$ was lower if the concentration of added arachidonic acid was reduced to 2 $\mu \mathrm{mol} / \mathrm{L}\left(\mathrm{IC}_{50}=4.3 \mu \mathrm{mol} / \mathrm{L}\right){ }^{6}$ The HUVECs, similar to other endothelial cells, ${ }^{34}$ are cells that are sensitive to the PGHS-inhibiting action of acetaminophen at phar- 
macologically relevant concentrations. An endothelial site of action of acetaminophen is particularly germane to its antipyretic action, in light of evidence that PGHS-2 is induced in brain endothelial cells during fever $^{35-37}$ and is required for the pyretic response. ${ }^{38,39}$

That acetaminophen's inhibitory strength in the endothelial cell is inversely proportional to the "peroxide tone" of the cell was also demonstrated by use of the cell-permeable organic hydroperoxide tert-butyl hydroperoxide. ${ }^{6}$ Treatment of HUVECs with increasing amounts of tert-butyl hydroperoxide completely abrogated the inhibitory effects of acetaminophen. These results have been duplicated in a pulmonary epithelial A549 cell line. ${ }^{40}$

Compared with these cells, the platelet is relatively resistant to the action of $0.6-$ to $1-\mathrm{g}$ oral doses of acetaminophen, which exert no effects on ex vivo aggregation and only moderate (40\%-70\%) inhibition of thromboxane $\mathrm{A}_{2}$ biosynthesis in most human volunteers studied; only infrequently is more substantial inhibition of thromboxane $\mathrm{A}_{2}$ biosynthesis and inhibition of aggregation found, perhaps related to an association with the highest concentrations of acetaminophen in plasma. ${ }^{4}$ The minimal effect of acetaminophen on platelets at doses that are antipyretic is consistent with our finding of an $\mathrm{IC}_{50}$ of $120 \mu \mathrm{mol} / \mathrm{L}$ for inhibition of thromboxane $\mathrm{A}_{2}$ biosynthesis in thrombin-activated platelets by acetaminophen. ${ }^{6}$ This can be explained by the fact that the explosive activation of phospholipase $\mathrm{A}_{2}$ in platelets by receptor-dependent stimuli results in a burst of $\mathrm{PGG}_{2}$ formation, which will cause the resistance of the platelet to the inhibitory action of acetaminophen. Furthermore, on activation, a substantial amount of the lipid hydroperoxide 12-hyroperoxyicosatetraenoic acid (12-HpETE) is formed via the platelet 12-lipoxygenase, ${ }^{41}$ which is a good PGHSPOX substrate. ${ }^{42}$ We have found that 12 -HpETE is a potent antagonist of acetaminophen action on purified PGHS-1 and likely contributes to the poor antiplatelet effect of acetaminophen in vivo. ${ }^{6}$ When stimulated with the same concentration of exogenous arachidonic acid, platelets are resistant to acetaminophen at concentrations that completely block PGHS activity in HUVECs (Fig 5).

Hydroperoxide-generating lipoxygenase enzymes (such as the 12/15 leukocyte type lipoxygenase and 5-lipoxygenase) also are highly expressed in inflammatory leukocytes, ${ }^{43-45}$ and their products, in addition to peroxynitrite and hydrogen peroxide generated by activated macrophages, might attenuate the action of acetaminophen in inflammatory settings, thereby contributing to the lack of an anti-inflammatory effect of the drug. Consistent with the lack of an anti-inflammatory effect of acetaminophen, we have found that the PGHS activity of the activated monocyte-macrophage cell line RAW 264.7 was very resistant to inhibition by acetaminophen. Low concentrations of acetaminophen that block PGHS activity in HUVECs by more than $90 \%$ actually stimulate PG biosynthesis in RAW 264.7 cells (Fig 5); only when the acetaminophen concentration reached $1 \mathrm{mmol} / \mathrm{L}$ did we observe inhibition of $\mathrm{PGE}_{2}$ synthesis by RAW cells stimulated with $2 \mu \mathrm{mol} / \mathrm{L}$ of exogenous arachidonic acid. These results strongly support the hypothesis that cellular "peroxide tone" determines the cell-selective inhibition of PGHSs by acetaminophen.

Thus the lack of appreciable antithrombotic ${ }^{3,46}$ and anti-inflammatory ${ }^{10}$ effects of acetaminophen may be ascribed to the resistance of platelets and activated macrophages to PGHS inhibition in vivo, whereas the antipyretic and analgesic effects of acetaminophen could be attributed to PG suppression in vascular endothelial cells ${ }^{6,34,47}$ and neurons. ${ }^{8,48}$ Future studies to assess the "peroxide tone" of cells and tissues in vivo and assess the relationship of such levels to acetaminophen's clinical action are required.

\section{Acetaminophen and "COX-3"}

The ability of acetaminophen to effectively inhibit CNS $\mathrm{PGE}_{2}$ production during fever ${ }^{15}$ and pain ${ }^{8}$ led to the hypothesis that an exquisitely acetaminophensensitive variant of PGHS exists within the $\mathrm{CNS}^{49,50}$ or vascular endothelium. ${ }^{28}$ In 2002 Chandrasekharan et $\mathrm{al}^{51}$ reported to have found such an enzyme within the canine cerebral cortex, which they designated "COX-3." This enzyme is the product of an alternatively spliced messenger ribonucleic acid (mRNA) of the COX-1 gene that is identical to COX-1 mRNA except that intron 1 is retained. Because it is a product of alternative splicing of PGHS-1 and not a genetically distinct entity, the name COX-3 has been rejected by many authors. ${ }^{52,53}$ Therefore we refer to it as PGHS-1b in this commentary. The PGHS- $1 b$ transcript (approximately 2.6 kilobases) was present at about $5 \%$ of the level of COX-1 mRNA in the dog cerebral cortex..$^{51}$

The investigators cloned and expressed canine PGHS- $1 b$, as well as murine PGHS- 1 and PGHS-2 enzymes in insect (Sf9) cells, and then compared their catalytic activities by measuring $\mathrm{PGE}_{2}$ generation in response to exogenous arachidonic acid. ${ }^{51}$ The expressed enzymes demonstrated quite heterogeneous activities, with PGHS-2 displaying the greatest catalytic activity. The PGHS-1 construct 
possessed only approximately $20 \%$ of the activity of PGHS-2, and PGHS-1b was only approximately $4 \%$ as active as PGHS-2. ${ }^{51}$ The reason for this variability was not determined.

This experimental system was used to compare the sensitivity of the 3 enzymes to inhibition by various compounds, including acetaminophen. The results were striking: Acetaminophen inhibited PGHS-1, PGHS-2, and PGHS- $1 \mathrm{~b}$ with $\mathrm{IC}_{50}$ values of 133 $\mu \mathrm{mol} / \mathrm{L}, 5887 \mu \mathrm{mol} / \mathrm{L}$, and $64 \mu \mathrm{mol} / \mathrm{L}$, respectively (in the presence of $5-\mu \mathrm{mol} / \mathrm{L}$ arachidonic acid). ${ }^{51}$ Moreover, with $30-\mu \mathrm{mol} / \mathrm{L}$ arachidonic acid, the potency of acetaminophen for all 3 isoforms was reduced, with only PGHS-1b being inhibited with micromolar concentrations $(460 \mu \mathrm{mol} / \mathrm{L})$. This inverse relationship between substrate (arachidonic acid) concentration and inhibitory potency accords with the hypothesis that higher amounts of $\mathrm{PGG}_{2}$ production antagonize the ability of acetaminophen to inhibit PGHS activity (discussed previously). ${ }^{6,21}$ The authors suggested that "COX-3 in the CNS may be an essential target of both analgesic/antipyretics and standard NSAIDs." ${ }^{51}$ However, a closer analysis of their data (and subsequent data from other investigators) suggests that PGHS-1b is not a pharmacologic target of acetaminophen's actions.

These studies were conducted before the discovery that the inhibitory potency of acetaminophen was an inverse function of the concentration of the enzyme. ${ }^{6}$ Thus an important limitation of the PGHS-1b study resulted from the authors' use of PGHS constructs having disparate activity levels. This experimental design confounds an accurate determination of the relative inhibitory potency of acetaminophen against PGHS-1, -2 , and $-1 b$, for reasons expressed previously. Because the ability of acetaminophen to inhibit PGHS enzymes is inversely proportional to enzyme concentration/activity (Figs 3 and 6), it would be predicted a priori that acetaminophen would inhibit the PGHS-1b construct with low catalytic activity more potently than cells transfected with either PGHS-1 or -2, which have higher catalytic activity. Therefore a meaningful comparison of the inhibitory potency of acetaminophen against different PGHS isoforms requires that the experimental conditions are designed to achieve comparable degrees of enzymatic activity among the 3 constructs. ${ }^{6}$ Future studies using purified PGHS-1, -2 , and $-1 b$ with equivalent catalytic activity are warranted before sound conclusions can be drawn regarding the relative potency of acetaminophen against the 3 proteins. The experiments reported by Chandrasekharan et $\mathrm{al}^{51}$ do not provide evidence that acetaminophen is

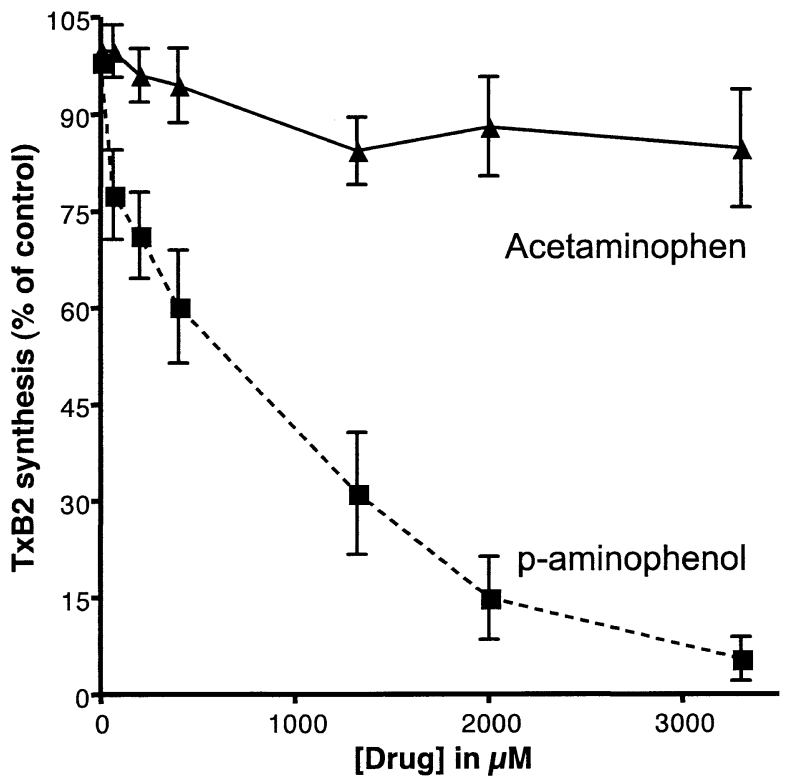

Fig 6. Comparison of inhibition of PGHS in platelets by acetaminophen and p-aminophenol. The synthesis of thromboxane $A_{2}$ in washed human platelets incubated with $20-\mu \mathrm{mol} / \mathrm{L}$ arachidonic acid was assayed in the presence of increasing concentrations of acetaminophen or p-aminophenol as described in reference 6 . The amount of thromboxane $\mathrm{B}_{2}$ (TxB2) present in the medium was determined by gas chromatography-negative ion chemical ionization-mass spectrometry as described in reference 65 and normalized to the value of the control (no inhibitor was added). Each data point represents the mean \pm SEM of at least 3 values.

more potent on PGHS-1b than on PGHS-1 and PGHS-2.

There is no evidence that a catalytically functional PGHS-1b protein is expressed in humans. Indeed, Chandrasekharan et $\mathrm{al}^{51}$ noted that intron 1 in humans differs from that in the dog by 1 nucleotide and therefore its inclusion in a human PGHS-1b would shift the remainder of the protein out of frame. Subsequently, Dinchuk et $\mathrm{al}^{54}$ cloned 12 human genomic fragments spanning this region and confirmed that intron 1 of human PGHS-1 is 94 nucleotides long and that inclusion of this intron in a human PGHS-1 would shift the remaining sequence of PGHS-1 out of frame. Furthermore, the rat $^{53}$ and mouse ${ }^{55}$ PGHS-1b transcripts are shifted out of frame by the retention of intron 1 and would not be expected to yield an active enzyme. Indeed, the rat PGHS- $1 \mathrm{~b}$ protein was recently cloned and does not have COX activity. ${ }^{53}$ Thus, in the absence of evidence for an acetaminophen-sensitive human 
PGHS-1b, there is no basis for implicating it in the pharmacology of acetaminophen in humans.

\section{Possible role for metabolites of acetaminophen}

Another hypothesis for cellular selectivity in the response to acetaminophen is that the metabolic fate of the drug differs among cells in a way that could modify its efficacy either through formation of an active metabolite or by accelerated inactivation of drug. There is abundant information on the biotransformation of acetaminophen, and some of this does indeed indicate such selectivity. Metabolism of acetaminophen largely occurs in the liver, via glucuronidation and sulfate conjugation (reviewed extensively in reference 56). A minor pathway of metabolism consists in the deacetylation of acetaminophen to yield p-aminophenol, a potent nephrotoxicant. In explorations of the mechanism of acetaminophen renal toxicity, deacetylation of acetaminophen to p-aminophenol was demonstrated in the mouse kidney. ${ }^{57}$ Subsequently, acetaminophen has been shown to undergo deacetylation to p-aminophenol followed by reacetylation back to acetaminophen, a "futile deacetylation" that confounds attempts to measure the extent of conversion of acetaminophen to p-aminophenol unless appropriate steps are taken to account for the futile deacetylation pathway. ${ }^{58}$ Thus it is of interest that acetaminophen is quite potent as an inhibitor of renal PGHS. ${ }^{59}$ Furthermore, inhibition of acetaminophen deacetylation reduces the nephrotoxicity caused by acetaminophen but not that resulting from p-aminophenol, suggesting an important role of this metabolic pathway in nephrotoxicity. ${ }^{60}$ On the basis of this and on evidence that $\mathrm{p}$-aminophenol is an inhibitor of PGHS in rat renal medulla, ${ }^{61}$ we have demonstrated that inhibition of biosynthesis of thromboxane $A_{2}$ in washed platelets is far greater with p-aminophenol than with acetaminophen (Fig 6). Although these findings provide a clear rationale for determining the extent of acetaminophen deacetylation as it relates to cellular selectivity in the action of acetaminophen, any role that cell- or tissue-specific deacetylation of acetaminophen may play in determining its clinical behavior remains to be explored.

A very recent study advances the hypothesis that a downstream metabolite of $p$-aminophenol participates in the analgesic properties of acetaminophen. ${ }^{62}$ Hogestatt et $\mathrm{al}^{62}$ demonstrated that, after its administration to the rat, acetaminophen is metabolized to the bioactive $N$-acylphenolamine compound $\mathrm{N}$-(4hydroxyphenyl)-5Z,8Z,11Z,14Z-eicosatetraenamide
(AM404), most likely via the enzymatic conjugation of p-aminophenol to arachidonic acid by fatty acid amide hydrolase. This is notable because AM404 is itself an analgesic agent ${ }^{63}$ that activates both vanilloid and cannabinoid receptors and inhibits the cellular reuptake of cannabinoid compounds. Hogestatt et $\mathrm{al}^{62}$ further reported that AM404 could inhibit both PGHS-1 and -2 in vitro, which may be relevant to the molecular basis of acetaminophen's inhibition of these enzymes. Additional studies are needed to prove that this metabolic pathway for acetaminophen is necessary for its analgesic behavior and that such pathways exist in humans. ${ }^{62}$

\section{CONCLUSIONS}

Acetaminophen is a commonly used antipyretic and analgesic agent that distinguishes itself from other NSAIDs and aspirin by its poor antiplatelet and anti-inflammatory actions. The pharmacologic basis for this distinct clinical behavior likely results from its unique ability to inhibit PGHS enzymes at the level of the POX catalytic site. Such an inhibitory mechanism would be predicted to exhibit a sensitivity to ambient peroxide levels, and this appears to be the case with acetaminophen. Whereas its analgesic and antipyretic effects likely follow PGHS inhibition within vascular endothelial cells and neurons, higher concentrations of lipid and nonlipid hydroperoxides within activated leukocytes and platelets prevent acetaminophen from substantially affecting such processes as inflammation and platelet thrombosis. Such a model explains acetaminophen's unique pharmacologic profile in humans.

\section{ADDENDUM}

After this article was accepted for publication, Qin et $\mathrm{al}^{66}$ reported the low-level expression of a functional PGHS-1 splice variant in human tissues, which was not more sensitive to inhibition by acetaminophen than the wild-type enzyme.

Dr Oates has received grant support from Merck-Frosst and McNeil. Drs Aronoff and Boutaud have not disclosed any conflict of interest with respect to the manuscript.

\section{References}

1. Funk CD. Prostaglandins and leukotrienes: advances in eicosanoid biology. Science 2001;294:1871-5.

2. Aronoff DM, Neilson EG. Antipyretics: mechanisms of action and clinical use in fever suppression. Am J Med 2001;111:304-15.

3. Catella-Lawson F, Reilly MP, Kapoor SC, Cucchiara AJ, DeMarco S, Tournier B, et al. Cyclooxygenase inhibitors 
and the antiplatelet effects of aspirin. N Engl J Med 2001;345:1809-17.

4. Lages B, Weiss HJ. Inhibition of human platelet function in vitro and ex vivo by acetaminophen. Thromb Res 1989;53:603-13.

5. Dubois RN, Abramson SB, Crofford L, Gupta RA, Simon LS, Van De Putte LB, et al. Cyclooxygenase in biology and disease. FASEB J 1998;12:1063-73.

6. Boutaud O, Aronoff DM, Richardson JH, Marnett LJ, Oates JA. Determinants of the cellular specificity of acetaminophen as an inhibitor of prostaglandin $\mathrm{H} 2$ synthases. Proc Natl Acad Sci U S A 2002;99:7130-5.

7. Feldberg W, Gupta KP, Milton AS, Wendlandt S. Effect of pyrogen and antipyretics on prostaglandin activity in cisternal c.s.f. of unanaesthetized cats. J Physiol 1973; 234:279-303.

8. Muth-Selbach US, Tegeder I, Brune K, Geisslinger G. Acetaminophen inhibits spinal prostaglandin $\mathrm{E}_{2}$ release after peripheral noxious stimulation. Anesthesiology 1999;91:231-9.

9. Green K, Drvota V, Vesterqvist O. Pronounced reduction of in vivo prostacyclin synthesis in humans by acetaminophen (paracetamol). Prostaglandins 1989; 37:311-5.

10. Seppala E, Nissila M, Isomaki $H$, Wuorela $H$, Vapaatalo H. Effects of non-steroidal antiinflammatory drugs and prednisolone on synovial fluid white cells, prostaglandin E2, leukotriene B4 and cyclic AMP in patients with rheumatoid arthritis. Scand J Rheumatol 1990;19:71-5.

11. Hinsberg O, Kast A. Ueber die Wirkung des Acetphenetidins. Zentralbl Med Wiss 1887;25:145-8.

12. von Mering J. Beiträge zur Kenntniss der Antipyretica. Ther Mon 1893;7:577-87.

13. Clissold SP. Paracetamol and phenacetin. Drugs 1986; 32:46-59.

14. Brodie BB, Axelrod J. The fate of acetophenetidin (phenacetin) in man and methods for the estimation of acetophenetidin and its metabolites in biological material. J Pharmacol Exp Ther 1949;97:58-67.

15. Feldberg W, Gupta KP. Sampling for biological assay of cerebrospinal fluid from the third ventricle in the unanaesthetized cat. J Physiol 1972;222:126P-9P.

16. Ohki S, Ogino N, Yamamoto S, Hayaishi O. Prostaglandin hydroperoxidase, an integral part of prostaglandin endoperoxide synthetase from bovine vesicular gland microsomes. J Biol Chem 1979;254:829-36.

17. Harvison PJ, Egan RW, Gale PH, Nelson SD. Acetaminophen as a cosubstrate and inhibitor of prostaglandin $\mathrm{H}$ synthase. Adv Exp Med Biol 1986;197:739-47.

18. Markey CM, Alward A, Weller PE, Marnett LJ. Quantitative studies of hydroperoxide reduction by prostaglandin $\mathrm{H}$ synthase. Reducing substrate specificity and the relationship of peroxidase to cyclooxygenase activities. J Biol Chem 1987;262:6266-79.
19. Tsai A, Kulmacz RJ. Tyrosyl radicals in prostaglandin $H$ synthase-1 and -2 . Prostaglandins Other Lipid Mediat 2000;62:231-54.

20. Rouzer CA, Marnett LJ. Mechanism of free radical oxygenation of polyunsaturated fatty acids by cyclooxygenases. Chem Rev 2003;103:2239-304.

21. Ouellet M, Percival MD. Mechanism of acetaminophen inhibition of cyclooxygenase isoforms. Arch Biochem Biophys 2001;387:273-80.

22. Boyd JA, Eling TE. Prostaglandin endoperoxide synthetase-dependent cooxidation of acetaminophen to intermediates which covalently bind in vitro to rabbit renal medullary microsomes. J Pharmacol Exp Ther 1981;219:659-64

23. Harvison PJ, Egan RW, Gale PH, Christian GD, Hill BS, Nelson SS. Acetaminophen and analogs as cosubstrates and inhibitors of prostaglandin $\mathrm{H}$ synthase. Chem Biol Interact 1988;64:251-66.

24. Moldeus P, Andersson B, Rahimtula A, Berggren M. Prostaglandin synthetase catalyzed activation of paracetamol. Biochem Pharmacol 1982;31:1363-8.

25. Moldeus P, Rahimtula A. Metabolism of paracetamol to a glutathione conjugate catalyzed by prostaglandin synthetase. Biochem Biophys Res Commun 1980;96:469-75.

26. Potter DW, Hinson JA. The 1-and 2-electron oxidation of acetaminophen catalyzed by prostaglandin $\mathrm{H}$ synthase. J Biol Chem 1987;262:974-80.

27. Masferrer JL, Zweifel BS, Seibert K, Needleman P. Selective regulation of cellular cyclooxygenase by dexamethasone and endotoxin in mice. J Clin Invest 1990;86:1375-9.

28. Mitchell JA, Akarasereenont P, Thiemermann C, Flower RJ, Vane JR. Selectivity of nonsteroidal antiinflammatory drugs as inhibitors of constitutive and inducible cyclooxygenase. Proc Natl Acad Sci U S A 1994;90:11693-7.

29. Riendeau D, Charleson S, Cromlish W, Mancini JA, Wong E, Guay J. Comparison of the cyclooxygenase-1 inhibitory properties of nonsteroidal anti-inflammatory drugs (NSAIDs) and selective COX-2 inhibitors, using sensitive microsomal and platelet assays. Can J Physiol Pharmacol 1997;75:1088-95.

30. Hanel AM, Lands WE. Modification of antiinflammatory drug effectiveness by ambient lipid peroxides. Biochem Pharmacol 1982;31:3307-11.

31. Dietz R, Nastainczyk W, Ruf HH. Higher oxidation states of prostaglandin $\mathrm{H}$ synthase. Rapid electronic spectroscopy detected two spectral intermediates during the peroxidase reaction with prostaglandin G2. Eur J Biochem 1988;171:321-8

32. Karthein R, Dietz R, Nastainczyk W, Ruf HH. Higher oxidation states of prostaglandin $\mathrm{H}$ synthase. EPR study of a transient tyrosyl radical in the enzyme during the peroxidase reaction. Eur J Biochem 1988;171:313-20.

33. Cushman DW, Cheung HS. Effect of substrate concentration on inhibition of prostaglandin synthetase of bull seminal vesicles by anti-inflammatory drugs and 
fenamic acid analogs. Biochim Biophys Acta 1976;424:449-59.

34. Kis B, Snipes JA, Simandle SA, Busija DW. Acetaminophen-sensitive prostaglandin production in rat cerebral endothelial cells. Am J Physiol Regul Integr Comp Physiol 2005;288:R897-902.

35. Cao C, Matsumura K, Yamagata K, Watanabe Y. Endothelial cells of the rat brain vasculature express cyclooxygenase-2 mRNA in response to systemic interleukin-1 beta: a possible site of prostaglandin synthesis responsible for fever. Brain Res 1996;733:263-72.

36. Inoue W, Matsumura K, Yamagata K, Takemiya T, Shiraki T, Kobayashi S. Brain-specific endothelial induction of prostaglandin $\mathrm{E}(2)$ synthesis enzymes and its temporal relation to fever. Neurosci Res 2002;44: 51-61.

37. Yamagata K, Matsumura K, Inoue W, Shiraki T, Suzuki $\mathrm{K}$, Yasuda S, et al. Coexpression of microsomal-type prostaglandin E synthase with cyclooxygenase-2 in brain endothelial cells of rats during endotoxin-induced fever. J Neurosci 2001;21:2669-77.

38. Li S, Ballou LR, Morham SG, Blatteis CM. Cyclooxygenase-2 mediates the febrile response of mice to interleukin-1beta. Brain Res 2001;910:163-73.

39. Li S, Wang Y, Matsumura K, Ballou LR, Morham SG, Blatteis CM. The febrile response to lipopolysaccharide is blocked in cyclooxygenase-2(-/-), but not in cyclooxygenase-1(-/-) mice. Brain Res 1999;825:86-94.

40. Lucas R, Warner TD, Vojnovic I, Mitchell JA. Cellular mechanisms of acetaminophen: role of cyclooxygenase. FASEB J 2005;19:635-7.

41. Johnson EN, Brass LF, Funk CD. Increased platelet sensitivity to ADP in mice lacking platelet-type 12lipoxygenase. Proc Natl Acad Sci U S A 1998;95: 3100-5.

42. Calzada C, Vericel E, Lagarde M. Low concentrations of lipid hydroperoxides prime human platelet aggregation specifically via cyclo-oxygenase activation. Biochem J 1997;325:495-500.

43. Fels AO, Pawlowski NA, Cramer EB, King TK, Cohn ZA, Scott WA. Human alveolar macrophages produce leukotriene B4. Proc Natl Acad Sci U S A 1982;79:786670 .

44. Martin TR, Altman LC, Albert RK, Henderson WR. Leukotriene B4 production by the human alveolar macrophage: a potential mechanism for amplifying inflammation in the lung. Am Rev Respir Dis 1984; 129:106-11.

45. Sun D, Funk CD. Disruption of 12/15-lipoxygenase expression in peritoneal macrophages. Enhanced utilization of the 5-lipoxygenase pathway and diminished oxidation of low density lipoprotein. J Biol Chem 1996;271:2405562.

46. Mielke CH Jr. Comparative effects of aspirin and acetaminophen on hemostasis. Arch Intern Med 1981;141: 305-10.
47. O'Brien WF, Krammer J, O'Leary TD, Mastrogiannis DS. The effect of acetaminophen on prostacyclin production in pregnant women. Am J Obstet Gynecol 1993;168: 1164-9.

48. Baumann J, von Bruchhausen F, Wurm G. Inhibition of prostaglandin synthetases derived from neuronal and glial cells and rat renal medulla by ortho-, meta-and para-substituted aminophenolic compounds. Prostaglandins Leukot Med 1983;10:319-29.

49. Botting RM. Mechanism of action of acetaminophen: is there a cyclooxygenase 3? Clin Infect Dis 2000;31(Suppl 5):S202-10.

50. Simmons DL, Botting RM, Robertson PM, Madsen ML, Vane JR. Induction of an acetaminophen-sensitive cyclooxygenase with reduced sensitivity to nonsteroid antiinflammatory drugs. Proc Natl Acad Sci U S A 1999;96: 3275-80.

51. Chandrasekharan NV, Dai H, Roos KL, Evanson NK, Tomsik J, Elton TS, et al. COX-3, a cyclooxygenase-1 variant inhibited by acetaminophen and other analgesic/ antipyretic drugs: cloning, structure, and expression. Proc Natl Acad Sci U S A 2002;99:13926-31.

52. Davies NM, Good RL, Roupe KA, Yanez JA. Cyclooxygenase-3: axiom, dogma, anomaly, enigma or splice error?-Not as easy as 1, 2, 3. J Pharm Pharm Sci 2004; 7:217-26.

53. Snipes JA, Kis B, Shelness GS, Hewett JA, Busija DW. Cloning and characterization of cyclooxygenase- $1 \mathrm{~b}$ (putative cyclooxygenase-3) in rat. J Pharmacol Exp Ther 2005;313:668-76.

54. Dinchuk JE, Liu RQ, Trzaskos JM. COX-3: in the wrong frame in mind [letter]. Immunol Lett 2003;86:121.

55. Shaftel SS, Olschowka JA, Hurley SD, Moore AH, O'Banion MK. COX-3: a splice variant of cyclooxygenase-1 in mouse neural tissue and cells. Brain Res Mol Brain Res 2003;119:213-5.

56. Prescott LF. The metabolism of paracetamol. Chap. 6. In: Paracetamol (acetaminophen): a critical bibliographic review. Bristol (UK): Taylor \& Francis; 1996. p. 67-102.

57. Carpenter HM, Mudge GH. Acetaminophen nephrotoxicity: studies on renal acetylation and deacetylation. J Pharmacol Exp Ther 1981;218:161-7.

58. Nicholls AW, Caddick S, Wilson ID, Farrant RD, Lindon JC, Nicholson JK. High resolution NMR spectroscopic studies on the metabolism and futile deacetylation of 4-hydroxyacetanilide (paracetamol) in the rat. Biochem Pharmacol 1995;49:1155-64.

59. Mattammal MB, Zenser TV, Brown WW, Herman CA, Davis BB. Mechanism of inhibition of renal prostaglandin production by acetaminophen. J Pharmacol Exp Ther 1979;210:405-9.

60. Newton R, Kuitert LM, Bergmann M, Adcock IM, Barnes PJ. Evidence for involvement of NFkappaB in the transcriptional control of COX-2 gene expression by IL-1beta. Biochem Biophys Res Commun 1997;237:2832. 
61. von Bruchhausen F, Baumann J. Inhibitory actions of desacetylation products of phenacetin and paracetamol on prostaglandin synthetases in neuronal and glial cell lines and rat renal medulla. Life Sci 1982;30:1783-91.

62. Hogestatt ED, Jonsson BA, Ermund A, Andersson DA, Bjork H, Alexander JP, et al. Conversion of acetaminophen to the bioactive $\mathrm{N}$-acyl phenolamine AM404 via fatty acid amide hydrolase-dependent arachidonic acid conjugation in the nervous system. J Biol Chem 2005;280:31405-12.

63. Guhring H, Hamza M, Sergejeva M, Ates M, Kotalla CE, Ledent $\mathrm{C}$, et al. A role for endocannabinoids in indomethacin-induced spinal antinociception. Eur J Pharmacol 2002;454:153-63.
64. Aronoff DM, Boutaud O, Marnett LJ, Oates JA. Inhibition of prostaglandin $\mathrm{H} 2$ synthases by salicylate is dependent on the oxidative state of the enzymes. J Pharmacol Exp Ther 2003;304:589-95.

65. Boutaud O, Brame CJ, Salomon RG, Roberts LJ II, Oates JA. Characterization of the lysyl adducts formed from prostaglandin $\mathrm{H} 2$ via the levuglandin pathway. Biochemistry 1999;38:9389-96.

66. Qin N, Zhang SP, Reitz TL, Mei JM, Flores CM. Cloning, expression, and functional characterization of human cyclooxygenase-1 splicing variants: evidence for intron 1 retention. J Pharmacol Exp Ther 2005;315:1298-305. E-pub 2005 Sep 1.

\section{ON THE MOVE?}

Don't miss a single issue of the journal! To ensure prompt service when you change your address, please photocopy and complete the form below.

Please send your change of address notification at least six weeks before your move to ensure continued service. We regret we cannot guarantee replacement of issues missed due to late notification.

JOURNAL TITLE:

Fill in the title of the journal here.

OLD ADDRESS:

Affix the address label from a recent issue of the journal here.

\section{NEW ADDRESS:}

Clearly print your new address here.

Name

Address

City/State/ZIP

OR FAX TO:

407-363-9661

OR E-mail:

elspcs@elsevier.com
OR PHONE:

800-654-2452

Outside the U.S., call

407-345-4000
Subscription Customer Service

6277 Sea Harbor Dr

Orlando, FL 32887 